\title{
Desempenho de sementes de soja sob condições diferentes de potencial osmótico
}

\author{
Soybean seed performance under different conditions of osmotic \\ potential
}

\section{Gilberto Antonio Freitas de Moraes ${ }^{1}$ Nilson Lemos de Menezes $^{2}$}

\section{RESUMO}

\begin{abstract}
Os cultivos sucessivos e as adubações necessárias acumulam resíduos minerais no solo, os quais alteram o potencial hídrico e afetam o desempenho fisiológico das sementes. Para avaliar a germinação e o vigor de sementes de soja, em condições variadas de potencial osmótico, conduziu-se um experimento em laboratório, no qual sementes de dois lotes da cultivar FEPAGRO RS 10, foram colocadas para germinar em papel-toalha umedecido com soluções de PEG 6000, $\mathrm{NaCl}$, $\mathrm{KCl}$ e $\mathrm{MgCl}_{2}$, para a obtenção dos potencias osmótico de zero; -0,05; -0,10;-0,20; -040 e-0,80 MPa. As sementes foram avaliadas através do teste de germinação (primeira contagem e contagem final), comprimento e massa seca das plântulas. A análise dos resultados permitiu concluir que o decréscimo nos potenciais osmóticos induzidos pelos solutos utilizados reduziu o potencial fisiológico das sementes de soja, sendo o vigor mais afetado do que a germinação. $O$ efeito da redução dos potenciais osmóticos sobre as sementes e plântulas depende da qualidade inicial das sementes, do tipo de sal e sua concentração. O PEG 6000 produz efeitos mais estressantes no desempenho das sementes de soja, do que os sais, quando há redução dos potenciais osmóticos até -0,80 MPa. O potencial osmótico de -0,80 MPa induzido por $\mathrm{MgCl}_{2}$ e PEG 6000 impede a germinação e a manifestação do vigor das sementes de soja.
\end{abstract}

Palavras-chave: germinação, vigor, estresse hídrico.

\section{ABSTRACT}

The mineral residues were accumulated in the soil due to successive fertilization as a consequence of annual cropping of the laud, wich change the hydric potential and affect the physiological performance of the seeds. The evaluation of the germination and vigor of the soybean seeds were performed in different conditions of the osmotic potential, seeds of lots $A$ and $B$ from FEPAGRO RS 10 cultivar were placed on a towel paper moistened with PEG 6000, $\mathrm{NaCl}, \mathrm{KCl}$ and $\mathrm{MgCl}_{2}$ to obtain the osmotic potentials: zero; $-0.05 ;-0.10$; $-0.20 ;-0.40$ and $-0.80 \mathrm{MPa}$. The results were evaluate by a standard germination test (a first and a final count), seedling length and dry weight. The statistical analysis indicated that the decrease in water potential induced by the treatments reduced seed quality and seed vigor was more affected than seed germination. The effect of reduced water potential on seeds and seedlings also depends on the initial quality of the seeds, the salt used and its concentration. PEG 6000 produced more stressing effects on soybean seed quality than the salts when the osmotic potential was up to $-0.80 \mathrm{MPa}$. The potential osmotic of - $0.80 \mathrm{MPa}$ inducet by $\mathrm{MgCl}_{2}$ and PEG 6000 hinders germination and decreases seed vigor of soybean seeds.

Key words: germination, vigor, water stress.

\section{INTRODUÇÃO}

A expansão da cultura da soja no Brasil, já atingindo as 40 milhões de toneladas, exige o uso de sementes de alta qualidade para o estabelecimento adequado de plantas no campo, evitando assim, maiores custos de produção.

A disponibilidade de água no solo é considerada uma das causas mais comuns da baixa germina-

\footnotetext{
${ }^{1}$ Engenheiro Agrônomo, Mestre, Professor Adjunto, Departamento de Biologia, Centro de Ciências Naturais e Exatas, Universidade Federal de Santa Maria (UFSM), Santa Maria-RS. E-mail: gilbertomoraesjr@mail.ufsm.br - Autor para correspondência.

${ }^{2}$ Engenheiro Agrônomo, Doutor, Professor Adjunto do Departamento de Fitotecnia, Centro de Ciências Rurais, UFSM.
} 
ção de sementes de soja, uma vez que períodos de estiagem são freqüentes na época de semeadura, porém a emergência e o desenvolvimento das plântulas está, também, na dependência de seu potencial fisiológico (MIAN \& NAFZIGER, 1994; ROSSETO et al.,1997). O polietilenoglicol tem sido utilizado para simular condições de campo, pois devido seu alto peso molecular não é absorvido pelas sementes, o que não acontece com os elementos minerais.

Estudando as relações entre qualidade fisiológica, disponibilidade hídrica e desempenho de duas variedades de soja, SÁ (1987) concluiu que o potencial hídrico -0,03 MPa revelou-se o mais adequado, porém a -0,20 MPa a germinação das sementes foi satisfatória. Potenciais matriciais entre - 0,40 e - $0,80 \mathrm{MPa}$ no solo, prejudicaram a germinação, mas não impediram sua ocorrência. McDONALD et al. (1988) determinaram que a germinação de sementes de soja em PEG 6000 mostrou-se muito reduzida a partir de -0,511 MPa. Utilizando soluções de $\mathrm{NaCl}$ e PEG 6000, BRACCINI et al. (1996a) determinaram que potenciais mais negativos afetaram mais o vigor do que a germinação de sementes de soja. Potenciais inferiores a $-0,30 \mathrm{MPa}$ foram críticos para os parâmetros estudados, destacando-se que o PEG 6000 apresentou um efeito totalmente adverso.

Os estresses salino e hídrico produzidos por $\mathrm{NaCl}, \mathrm{CaCl}_{2}, \mathrm{Na}_{2} \mathrm{SO}_{4}$ ou PEG 6000 exerceram efeitos negativos na germinação e no vigor de sementes de soja, sendo que nas maiores concentrações, estes efeitos foram mais acentuados em sementes com baixo vigor do que naquelas com alto vigor (SANTOS et al., 1992; BRACCINI et al., 1998). Os resultados adversos produzidos por estes solutos podem ter sido devido ao efeito osmótico e/ou iônico que dificultam a absorção de água ou facilitam a penetração de íons nas células (Van DER MOEZEL \& BELL, 1987). A diminuição da germinação também pode ser atribuída a menor mobilização das reservas, menor síntese e atividade enzimática ou mudanças na turgescência celular (BRUNI\&LEOPOLD, 1992; DELL'AQUILLA, 1992;BEWLEY \& BLACK, 1994).

Sementes de soja com níveis de vigor e teores de água inicial distintos, germinadas no solo e em soluções de PEG 6000, mostraram que existe relação entre o teor de água inicial e sua qualidade fisiológica. Potenciais hídricos de -0,20 e -0,40 MPa causaram redução da emissão da raiz primária e, sob - $0,40 \mathrm{MPa}$ a emergência de plântulas foi reduzida (ROSSETO et al., 1997).

O presente trabalho teve por objetivo avaliar a germinação e o vigor de dois lotes de sementes de soja em diferentes potenciais osmóticos obtidos a partir do polietilenoglicol e dos cloretos de sódio, potássio e magnésio.

\section{MATERIALEMÉTODOS}

O trabalho foi realizado no Laboratório Didático e de Pesquisas em Sementes (LDPS), no Departamento de Fitotecnia da Universidade Federal de Santa Maria (UFSM), RS.

Foram utilizadas sementes de soja [Glycine $\max ($ L.) Merrill], cultivar FEPAGRO RS 10, safras 1998/ 1999 e 1999/2000, correspondendo aos lotes B e A, respectivamente, seu potencial fisiológico avaliado por meio de testes de germinação e vigor, em soluções de cloreto de sódio $(\mathrm{NaCl})$, cloreto de potássio $(\mathrm{KCl})$, cloreto de magnésio $\left(\mathrm{MgCl}_{2}\right)$ e polietilenoglicol (PEG 6000) nos níveis de potenciais osmóticos correspondentes a zero; $-0,05 ;-0,10 ;-0,20 ;-0,40$ e $-0,80 \mathrm{MPa}$. O nível zero correspondeu à testemunha, na qual se utilizou água destilada.

As quantidades de $\mathrm{NaCl}, \mathrm{KCl}$ e $\mathrm{MgCl}_{2}$ para se obter os referidos potenciais osmóticos foram calculadas a partir da equação de Van't Hoff (SALISBURY \& ROSS, 1992), já as quantidades de PEG 6000 foram obtidas com base em MICHEL \& KAUFMANN (1973).

O Teste de Germinação foi realizado utilizando-se quatro repetições de 50 sementes por tratamento para cada lote. As sementes foram colocadas em rolos de papel-toalha umedecidas, num volume equivalente a 2,5 vezes o peso do papel seco. Os rolos foram colocados em sacos plásticos e levados ao germinador a $25^{\circ} \mathrm{C}$. Foram efetuadas contagens aos quatro e aos seis dias, após a instalação do experimento. Na primeira contagem, usada como teste de vigor, foram retiradas as plântulas normais com comprimento igual ou superior a seis centímetros e os resultados expressos em porcentagem média de plântulas normais.

Foram também avaliados o comprimento e a massa seca de plântulas, de acordo com a metodologia proposta por KRZYZANOWSKY et al., (1991), utilizando-se quatro repetições de 25 sementes por tratamento e por lote. As medições foram efetuadas após quatro dias da instalação do experimento e os resultados expressos em centímetros e miligramas, respectivamente.

O delineamento utilizado foi inteiramente casualizado, em esquema fatorial (dois níveis de vigor, quatro produtos químicos e seis níveis de potenciais osmóticos). As variáveis expressas em porcentagem (Teste de Germinação e primeira contagem), foram transformadas previamente em arco seno \%/100 ${ }^{1 / 2}$. Os resultados foram submetidos à análise de variância e regressão.

\section{RESULTADOS E DISCUSSÃO}

A análise da variância dos resultados do experimento indicou, para todas as variáveis, que não ocorreu interação significativa entre os fatores lotes de sementes, produtos químicos e potenciais 
osmóticos. Por outro lado, as interações lotes $\mathrm{x}$ produtos químicos, lotes $\mathrm{x}$ potenciais osmóticos e produtos químicos $\mathrm{x}$ potenciais osmóticos foram significativas $(\mathrm{P}>0,05)$.

Os resultados observados na figura 1 mostram uma redução na porcentagem de germinação dos lotes de sementes de soja, a medida que o potencial das soluções osmóticas diminuiu. A germinação manteve-se acima de $80 \%$, quando se utilizou a solução de $\mathrm{NaCl}$ até as concentrações de - 0,20 MPa e-0,10 MPa, nos lotes A e B, respecti-vamente. A partir destes níveis de potencial, a redução da germinação foi mais drástica.

Também usando

$\mathrm{NaCl}$ como agente osmótico, SANTOS (1996) e BRACCINI et al.(1996a) observaram decréscimo semelhante na germinação de sementes de soja. Para Van DER MOEZEL \& BELL (1987), o $\mathrm{NaCl}$ afeta a germinação pelo efeito osmótico e/ou pelo efeito iônico, dificultando a absorção de água ou facilitando a penetração de íons nas células.

Para as soluções osmóticas de $\mathrm{KCl}$ a porcentagem de germinação manteve se acima de $80 \%$ até $-0,10 \mathrm{MPa}$ para os dois lotes de sementes de soja. Após este valor, houve redução progressiva para ambos os lotes. Em -0,80 MPa de $\mathrm{KCl}$ a germinação foi reduzida para os dois lotes de sementes, embora superiores aos valores encontrados para $\mathrm{NaCl}$.

Com relação as sementes de soja submetidas as soluções osmóticas

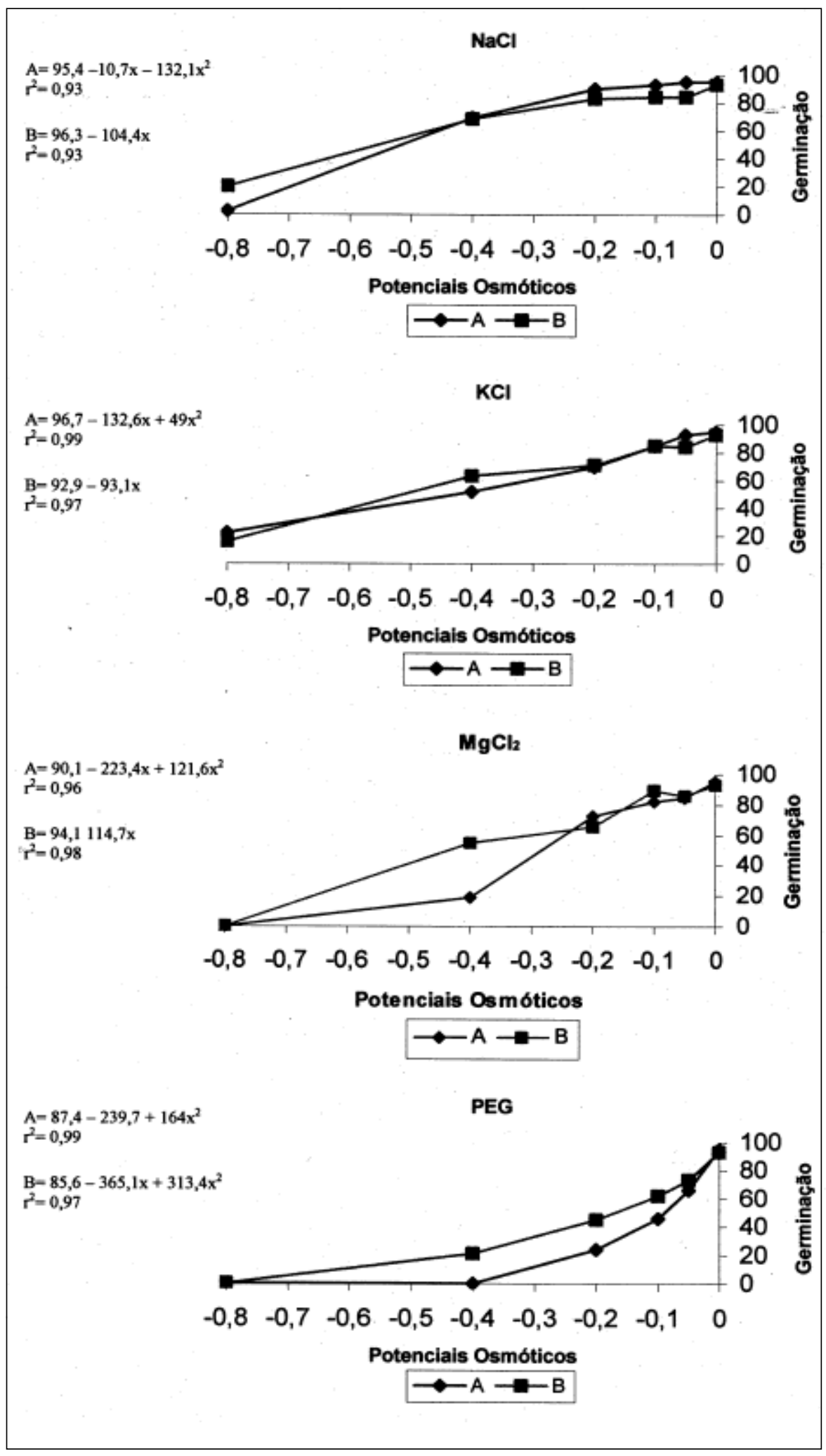

Figura 1 - Germinação dos lotes A e B de sementes de soja, cv. FEPAGRO RS 10, sbmetidas a potenciais osmóticos a partir de cloretos de sódio, potássio, magnésio e polietilenoglicol, B = safra 1998/1999, A = safra 1999/2000.

Ciência Rural, v. 33, n. 2, mar-abr, 2003. 
de $\mathrm{MgCl}_{2}$, observou-se que a porcentagem de germinação diminuiu para os dois lotes à medida que os potenciais decresceram. A partir de -0,05 MPa houve redução na germinação no lote $\mathrm{A}$, porém para o lote $\mathrm{B}$ o mesmo comportamento foi observado a partir de $-0,10$ $\mathrm{MPa}$. Nos potenciais osmóticos de -0,10 a -0,40 MPa o lote B manteve-se com porcentagens de germinação superiores ao lote A.

As sementes de soja tiveram sua capacidade germinativa mais afetada pelo PEG 6000 do que pelos demais sais, ficando mais evidente à medida que os potenciais osmóticos decresceram. McDONALD et al. (1988) observaram que a germinação de sementes de soja em soluções de polietilenoglicol foi bastante reduzida a partir de $-0,511$ $\mathrm{MPa}$, indo ao encontro dos resultados obtidos por BRACCINI et al. (1996a). Isto pode ter relação com o fato de que as soluções de PEG apresentam alta viscosidade, comprometendo a disponibilidade de $\mathrm{O}_{2}$ para as sementes, reduzindo o seu poder germinativo (YOON et al., 1997).

O decréscimo no vigor que se observa na figura 2 vem ao encontro dos resultados obtidos por BRACCINI et al. (1996a). BRUNI \& LEOPOLD (1992) sugerem que essa redução é causada pela deficiência de água, o que provoca a perda progressiva da turgescência protoplasmática e um aumento na concentração de solutos. Des-

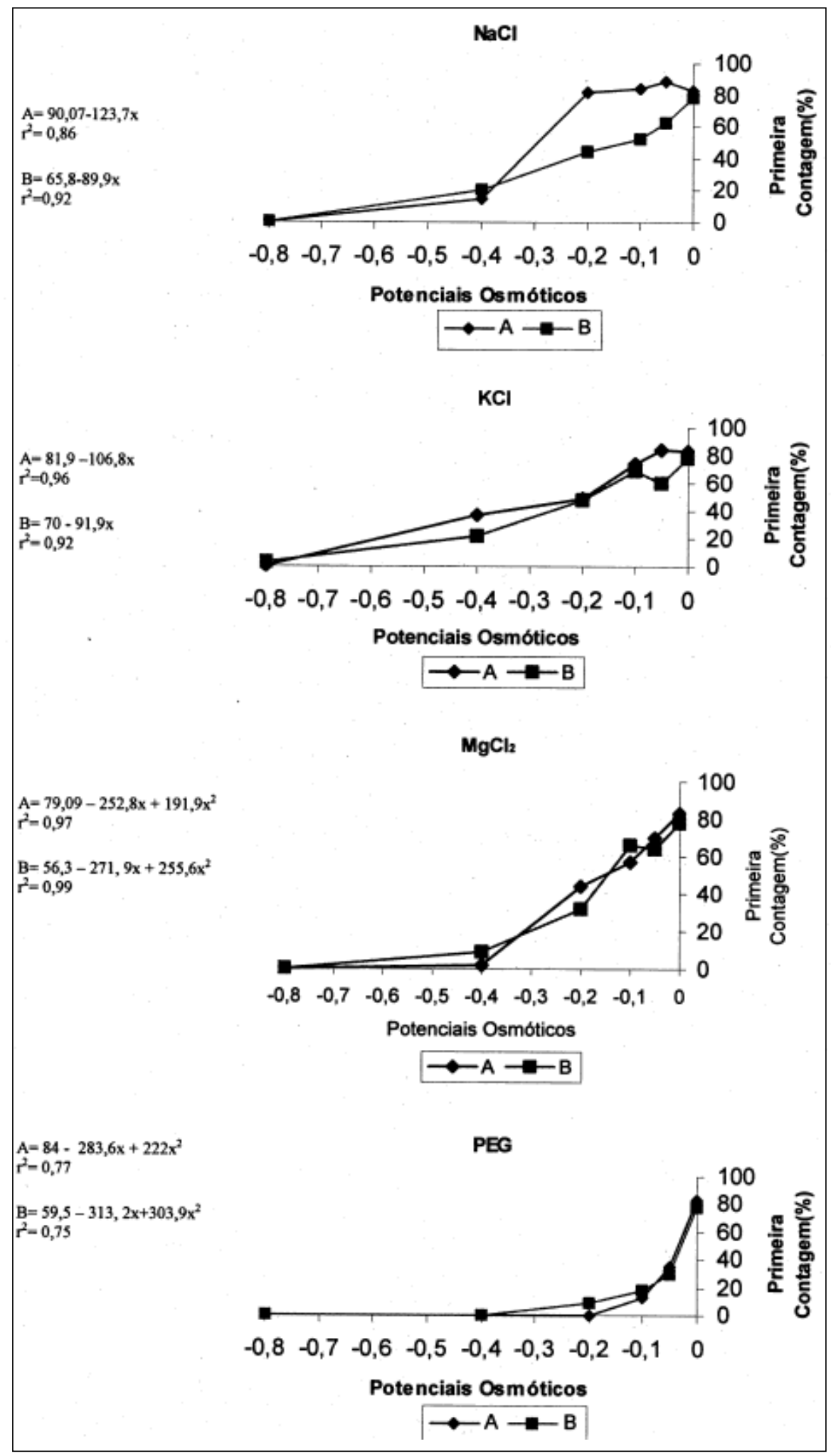

Figura 2 - Primeira contagem do teste de germinação dos lotes A e B de sementes de soja, cv. FEPAGRO RS 10, submetidas a potenciais osmóticos a partir dos cloretos de sódio, potássio de magnésio e polietilenoglicol. B = safra 1998/1999, A = safra 1999/2000.

Ciência Rural, v. 33, n. 2, mar-abr, 2003. 
ses efeitos resulta, inicialmente, um distúrbio na função celular e, por fim, danos no sistema de biomembranas.

Comparando-se os resultados de vigor na primeira contagem (Figura 2) com os de germinação na contagem final (Figura 1), observa-se que o vigor das sementes de soja foi mais afetado que a sua germinação. $\mathrm{Na}$ presença de $\mathrm{NaCl}$, o vigor de ambos os lotes foi em torno de $40 \%$ em - $0,40 \mathrm{MPa}$ e em - $0,80 \mathrm{MPa}$ foi considerado nulo.Este fato está de acordo com SÁ (1987), que detectou valores muito reduzidos em -0,60 MPa e ausentes em -0,80 MPa.

$\mathrm{O}$ vigor das sementes em soluções de $\mathrm{KCl}$ (Figura 2) também decresceu progressivamente à medida que os potenciais osmóticos tornaram-se mais negativos. $\mathrm{O}$ lote $\mathrm{B}$ apresentou vigor muito semelhante nas soluções de $\mathrm{NaCl}$ e $\mathrm{KCl}$, em todos os níveis de potenciais osmóticos. Já o lote A teve redução do vigor a partir de -0,10 MPa na solução de $\mathrm{NaCl}$. Em -0,20 e -0,40 MPa, o vigor desse lote, mesmo reduzido, foi sempre superior ao do lote B. Estes resultados concordam com aqueles obtidos por ROSSETO et al. (1997).

Quando as sementes de soja foram submetidas às soluções osmóticas de $\mathrm{MgCl}_{2}$, observou-se que o lote $\mathrm{A}$ apresentou o maior vigor no nível zero de potencial osmótico, decrescendo com a redução do potencial das soluções. O lote B foi menos vigoroso em todos os potenciais osmóticos estudados, confirmando as expectativas iniciais, uma vez que o mesmo foi produzido na safra anterior àquela do lote $\mathrm{A}$. BRACCINI et al. (1996b) também constataram que sementes de soja com baixo vigor são mais influenciadas pelo estresse hídrico do que sementes com alto vigor. Para McDONALD et al. (1988), sementes envelhecidas perdem a capacidade de manter uma alta pressão de turgor o que pode justificar o desempenho do lote B.

Na presença de PEG 6000, os lotes A e B mostraram comportamento semelhantes quanto ao seu vigor. Entretanto, o lote $\mathrm{A}$ apresentou maior índice de vigor em todos os potenciais avaliados, exceto em $-0,80$ MPa onde não se detectou sementes germinadas em nenhum dos lotes. Estes dados confirmam os resultados de BRACCINI et al. (1998), onde o desempenho de sementes de soja sob estresse hídrico está na dependência de sua qualidade fisiológica inicial.

$\mathrm{Na}$ figura 3, observa-se que o comprimento das plântulas de soja sofreu redução à medida que os potenciais osmóticos decresceram, indo ao encontro dos resultados encontrados por SANTOS et al. (1992). A restrição hídrica diminui a velocidade dos processos fisiológicos e bioquímicos, restringindo o desenvolvimento. Esta redução ocorreu de modo similar ao ocorrido com os resultados de vigor na primeira conta- gem e com a germinação na contagem final. DELL'AQUILLA (1992) atribui a diminuição no crescimento à mudanças na turgescência celular, em decorrência da redução da síntese de proteínas no embrião em situação de estresse hídrico.

Em soluções de $\mathrm{NaCl}$, observa-se que no lote A, o comprimento de plântulas manteve-se superior até - $040 \mathrm{MPa}$, a partir do qual a diminuição do comprimento foi evidente, tornando-se idêntico para os dois lotes. Este fato confirma os resultados de BRACCINI et al. (1996a) em cujos estudos potenciais osmóticos inferiores a -0,30 MPa são críticos para avaliar o vigor de sementes de soja.

O comprimento de plântulas, em soluções de $\mathrm{KCl}$ e $\mathrm{MgCl}_{2}$ diminuiu com a redução do potencial osmótico. Para os dois sais, o lote A mantevese com comprimento de plântulas elevado até $-0,10$ MPa. Em -0,20 MPa e em potenciais inferiores o maior comprimento foi das plântulas do lote $\mathrm{B}$, contrariando o esperado. Para POPINIGIS (1985), sementes com baixo vigor podem apresentar um tegumento mais permeável, facilitando a absorção de água mesmo que esta se encontre pouco disponível.

Com a utilização de PEG 6000, a redução do comprimento de plântulas foi progressiva a partir do potencial zero, com melhor desempenho para o lote A, chegando a valores insignificantes a -0,20 MPa e, ausentes nos potenciais subseqüentes, ficando desta forma, evidenciado o grande efeito estressante do PEG. Entretanto, observou-se um melhor desempenho do lote A em relação ao $\mathrm{B}$. Reduções significativas no comprimento de plântulas por PEG 6000 também foram obtidas por BRACCINI et al. (1996a e 1998) a partir de $-0,30 \mathrm{MPa}$.

Pela figura 4 , nota-se que a massa seca de plântulas decresceu com a diminuição dos potenciais osmóticos. Resultados análogos foram obtidos por SANTOS et al. (1996) e BRACCINI et al. (1996a). A redução da massa seca de plântulas em função da restrição hídrica se dá devido à demora dos processos fisiológicos e bioquímicos ou pela dificuldade de hidrólise e a mobilização das reservas armazenadas nas sementes (SÁ, 1987; BEWLEY \& BLACK, 1994).

Em soluções de $\mathrm{NaCl}$, o lote A apresentou maior massa seca de plântulas do que o lote $\mathrm{B}$, em todos os potenciais avaliados, exceto em -0,40 MPa onde não se constatou diferença, enquanto que em $\mathrm{KCl}$, o lote A apresentou maior massa seca de plântulas até $-0,10 \mathrm{MPa}$.

Para $\mathrm{MgCl}_{2}$, além da redução de massa seca de plântulas observada nos outros sais, verificou-se que o lote $\mathrm{B}$, a partir de $-0,40 \mathrm{MPa}$ mostrou maior acúmulo de massa seca de plântulas do que o lote A. 


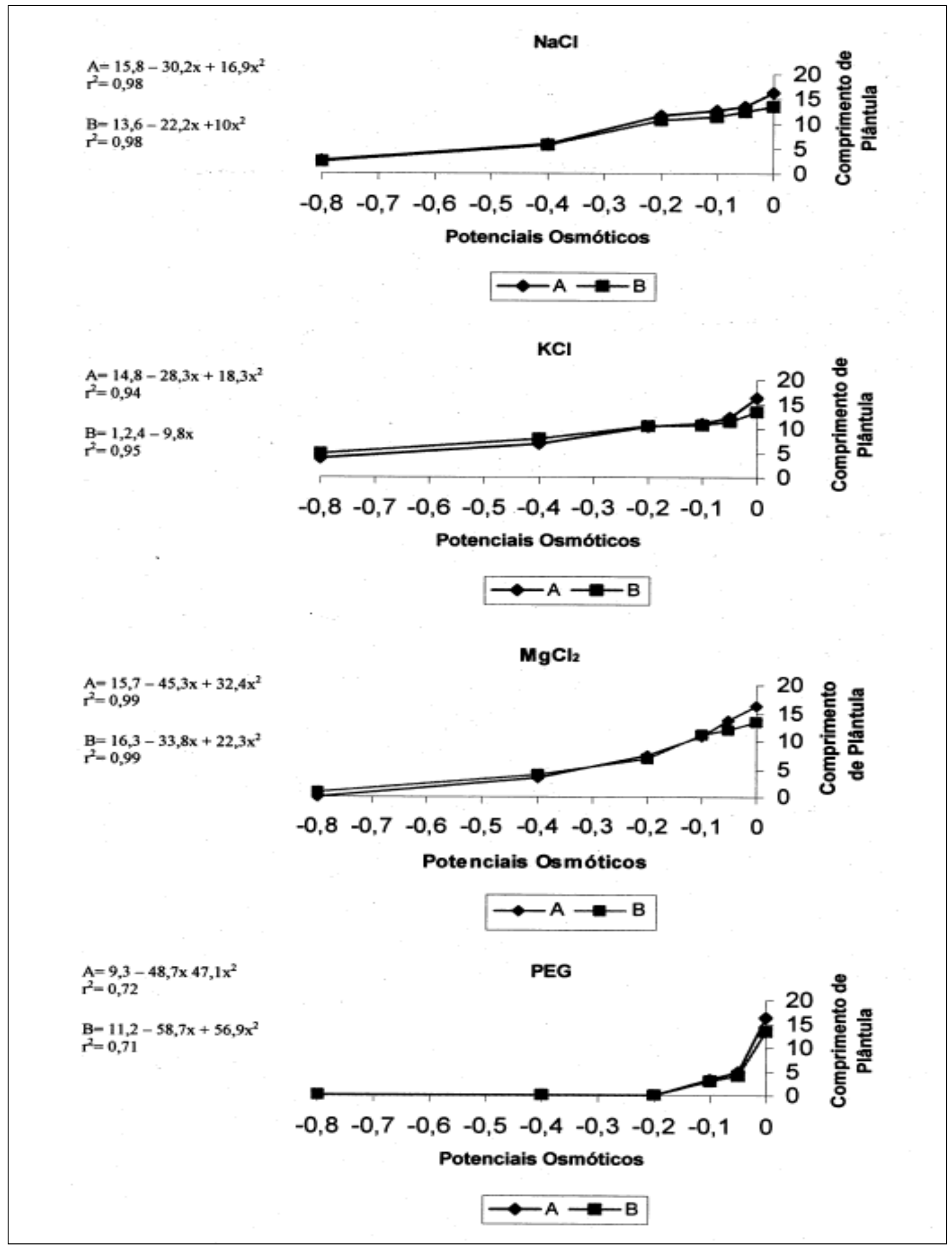

Figura 3 - Comprimento de plântulas dos lotes A e B de soja, cv. FEPAGRO RS 10, submetidas a potenciais osmóticos a partir dos cloretos de sódio, potássio, de magnésio e polietilenoglicol. B = safra 1998/1999, A = safra 1999/2000.

Ciência Rural, v. 33, n. 2, mar-abr, 2003. 


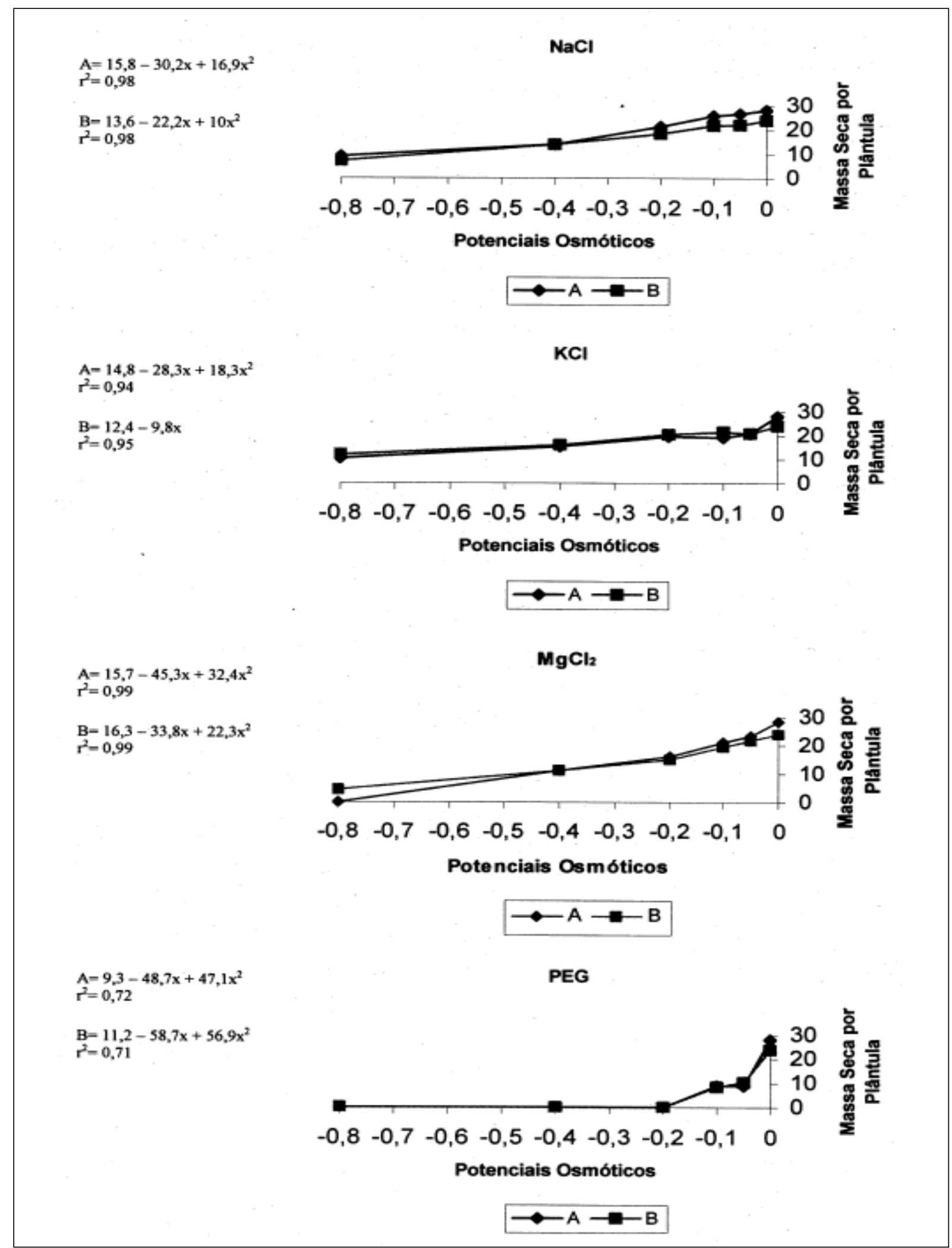

Figura 4 - Massa seca de plântulas dos lotes A e B de sementes de soja, cv. FEPAGRO RS 10, submetidas a potenciais osmóticos a partir dos cloretos de sódio, potássio, de magnésio e polietilenoglicol. B = safra 1998/1999, A = safra 1999/2000.

Ciência Rural, v. 33, n. 2, mar-abr, 2003. 
Esses resultados poderiam ser atribuídos ao fato de que sementes mais velhas absorvem água mais facilmente em virtude da maior permeabilidade de seu tegumento, como afirmou POPINIGIS, (1985). $\mathrm{O} \mathrm{MgCl}_{2}$, a -0,80 MPa, proporcionou o menor acúmulo de massa seca de plântulas comparado com os demais sais, sugerindo que os efeitos negativos causados pelo estresse salino podem estar relacionados com o tipo de sal utilizado.

Em relação ao PEG 6000, houve uma redução progressiva na massa seca das plântulas dos lotes $\mathrm{A}$ e $\mathrm{B}$, à medida que diminuiu o potencial osmótico das soluções, comportamento bastante semelhante ao ocorrido com o comprimento de plântulas. Resultados desta ordem também foram encontrados por BRACCINI et al. (1996a e 1998).

\section{CONCLUSÃO}

O decréscimo nos potenciais osmóticos induzidos por PEG 6000, $\mathrm{NaCl}, \mathrm{KCl}$ e $\mathrm{MgCl}_{2}$ dificultam a expressão da qualidade fisiológica das sementes de soja, sendo o vigor mais afetado do que a germinação.

$\mathrm{O}$ efeito da redução dos potenciais osmóticos sobre as sementes e plântulas de soja depende da qualidade inicial das sementes, do tipo de sal e sua concentração.

O PEG 6000 produz efeitos mais estressantes na qualidade das sementes de soja, do que $\mathrm{NaCl}, \mathrm{KCl}$ e $\mathrm{MgCl}_{2}$, quando há redução dos potenciais osmóticos até $-0,80 \mathrm{MPa}$.

O potencial osmótico de - $0,80 \mathrm{MPa}$ induzido por $\mathrm{MgCl}_{2}$ e por PEG 6000 impede a germinação e a manifestação do vigor das sementes de soja.

\section{REFERÊNCIASBIBLIOGRÁFICAS}

BEWLEY, J.D.; BLACK, M. Seeds: physiology of development and germination. 2. ed. New York: Plenum, 1994. 445p.

BRACCINI, A.L. et al. Germinação e vigor de sementes de soja sob estresse hídrico induzido por soluções de cloreto de sódio, manitol e polietilenoglicol. Revista Brasileira de Sementes, Brasília, v.18, n.1, p.10-16, 1996a.

BRACCINI, M.C.L. et al. Efeito do potencial hídrico do solo e do substrato embebido com manitol sobre a germinação de sementes de soja. Revista Brasileira de Sementes, Brasília, v.18, n.2, p.200-207, 1996b.
BRACCINI, A.L. et al. Influência do potencial hídrico induzido por polietilenoglicol na qualidade fisiológica de sementes de soja. Pesquisa Agropecuária Brasileira, Brasília, v.33, n.9, p.1451-1459, 1998.

BRUNI, F.B.; LEOPOLD, A.C. Cytoplasmic glass formation in maize embryos. Seed Science Research, New York, v.2, n.4, p.251-253, 1992.

DELL'AQUILA, A. Water uptake and protein synthesis in germinating wheat embryos under osmotic stress of polyethylene glycol. Annals of Botany, Camberra, v.69, n.2, p.167-171, 1992.

KRZYZANOWKY, F. C.; FRANÇA NETO, J. B.; HENNING, A. A. Relato dos testes de vigor disponíveis para grandes culturas. Informativo ABRATES, Londrina, v.1, n.2, p.15-50, 1991.

McDONALD, M.B.Jr.; VERTUCCI, C.W.; ROOS, E.E. Soybean seed imbibition: water absortion by seed parts. Crop Science, Madison, v.28, n.6, p.993-997, 1988.

MIAN, M.A.R.; NAFZIGER, E.D. Seed size and water potential effects on germination and seedling growth of winter wheat. Crop Science, Madison, v.34, n.1, p.169-171, 1994.

MICHEL, B.E.; KAUFMANN, M.R. The osmotic potential of polyethylene glycol 6000. Plant Physiology, Lancaster, v.51, n.6, p.914-916, 1973.

POPINIGIS, F. Fisiologia da semente. Brasília : AGIPLAN, 1985. 289p.

ROSSETTO, C.A.V. et al. Efeito da disponibilidade hídrica do substrato, da qualidade fisiológica e do teor de água inicial das sementes de soja no processo de germinação. Scientia Agricola, Piracicaba, v.54, n.1/2, p.97-105, 1997.

SÁ, M.E. Relações entre qualidade fisiológica, disponibilidade hídrica e desempenho de sementes de soja (Glycine max (L.) Merrill). 1987. 147f. Tese (Doutorado) ESALQ / USP.

SALISBURY, F.B.; ROSS, C.W. Plant physiology. 4. ed. California : Wadsworth, 1992. 682p.

SANTOS, V.L.M. et al. Efeito do estresse salino e hídrico na germinação e vigor de sementes de soja. Revista Brasileira de Sementes, Brasília, v.14, n.2, p.189-194, 1992.

SANTOS, V.L.M. et al. Utilização do estresse salino na avaliação da qualidade das sementes de genótipos de soja (Glycine $\max ($ L.) Merrill). Revista Brasileira de Sementes, Brasília, v.18, n.1, p.63-72, 1996.

Van DER MOEZEL, P.G.; BELL, D.T. The effect of salinity on the germination of some Western Australian Eucalyptus and Melaleuca species. Seed Science \& Technology, Zürich, v.15, n.1, p.239-246, 1987.

YOON, Y.; LANG, H.J.; COBB, B.G. Priming with salt solutions improves germination of pansy seed at high temperatures. HortScience, Alexandria, v.32, n.2, p.248-250, 1997. 